Article

\title{
Cutting Forces and Chip Shaping When Finish Turning of 17-4 PH Stainless Steel under Dry, Wet, and MQL Machining Conditions
}

\author{
Kamil Leksycki ${ }^{1} * *$ (D) Eugene Feldshtein ${ }^{1}$, Joanna Lisowicz ${ }^{2}$, Roman Chudy ${ }^{3, *}$ (i) \\ and Roland Mrugalski 4 \\ 1 Institute of Mechanical Engineering, University of Zielona Gora, 4 Prof. Z. Szafrana street, \\ 65-516 Zielona Gora, Poland; e.feldsztein@iim.uz.zgora.pl \\ 2 Faculty of Mechanical Engineering and Aeronautics, Rzeszow University of Technology, \\ 12 Al. Powstancow Warszawy street, 35-959 Rzeszow, Poland; j.lisowicz@prz.edu.pl \\ 3 Faculty of Mechanical Engineering, Opole University of Technology, 5 Mikolajczyka street, \\ 45-271 Opole, Poland \\ 4 Volkswagen Motor Polska sp. z o.o., 1 Strefowa street, 59-101 Polkowice, Poland; \\ roland.mrugalski@vwmp.pl \\ * Correspondence: k.leksycki@iim.uz.zgora.pl (K.L.); r.chudy@po.edu.pl (R.C.)
}

Received: 6 August 2020; Accepted: 1 September 2020; Published: 3 September 2020

\begin{abstract}
This paper analyses three components of total cutting force and chip shape changes when finish turning 17-4 PH (precipitation hardening) stainless steel. A Finite Element Method (FEM) simulation of cutting forces was also performed using the Johnson-Cook constitutive model. The results were compared with those obtained from experimental studies. Variable feeds of $0.05-0.4 \mathrm{~mm} / \mathrm{rev}$ and depth of cut of $0.2-1.2 \mathrm{~mm}$ with a cutting speed of $220 \mathrm{~m} / \mathrm{min}$ were used. The studies were carried out under dry and wet cooling conditions and with the use of minimum quantity lubrication (MQL). This research was realized based on the Parameter Space Investigation (PSI) method. Statistical analysis of the obtained results was carried out using Statistica-13 software. It was found that the cutting force $F_{\mathrm{c}}$ and feed force $F_{\mathrm{f}}$ depend on the depth of cut and feed, and the passive force $F_{\mathrm{p}}$ depends mainly on the feed. Compared to dry cutting conditions, a reduction of $43 \%$ and $39 \%$ of the cutting force $F_{\mathrm{c}}$ was achieved for wet machining and MQL machining, respectively. Regardless of the cooling conditions, a favorable chip shape was registered for $a_{p}=1-1.1 \mathrm{~mm}$ and $f=0.25-0.3 \mathrm{~mm} / \mathrm{rev}$. Compared to the experimental studies, the FEM simulation showed differences of $\sim 13 \%$ for the cutting force $F_{\mathrm{c}}$ and of $\sim 36 \%$ for the feed force $F_{\mathrm{f}}$.
\end{abstract}

Keywords: finish turning; stainless steel; cooling methods; cutting forces; FEM simulation; Johnson-Cook constitutive model; chip shaping

\section{Introduction}

17-4 $\mathrm{PH}(\mathrm{X} 5 \mathrm{CrNiCuNb} 16-4)$ stainless steel is a relatively new material that has had increased use in industry [1,2] and that, due to its physical and mechanical properties, is considered to be difficult for cutting material. Good machinability is defined as the optimum combination of low cutting forces, high surface quality, low energy consumption, and good chip breaking [3].

Turning is a basic and important machining process and is widely used for production [4]. The determination of cutting forces is important for the design of cutting tools and devices [5]. During the turning process, long and tangled chips are formed because the rake face of the cutting tool is in constant contact with the work-piece surface. As a result, chips can become entangled around the cutting tool and cause difficulties in getting out of the machining zone $[4,6]$. 
Litak et al. [7] tested cutting forces while turning E-Z6NCT25 (X6NiCrTiMoVB25-15-2) stainless steel with a cutting depth of 1.0-2.3 mm, a constant spindle speed of $780 \mathrm{rpm}$, and a constant feed of $0.25 \mathrm{~mm} / \mathrm{rev}$. As the depth of cut increased, the cutting forces increased, and parametric and unstable vibrations were created. Servaraj et al. [8] analyzed the effect of cutting speed and feed on cutting forces. Two ASTM stainless steels, namely 5A (X2CrNiMoN25-7-4) and 4A (X2CrNiMoN22-5-3), were turned with cutting speeds of $80-120 \mathrm{~m} / \mathrm{min}$, feeds of $0.04-0.12 \mathrm{~mm} / \mathrm{rev}$, and a constant depth of cut of $0.5 \mathrm{~mm}$ under dry cutting conditions. The value of the feed had the greatest impact on the values of the cutting forces tested. Krolczyk et al. [9] examined the optimum turning conditions of 1.4462 (X2CrNiMoN22-5-3) stainless steel with three different cemented carbide tools, feeds of 0.2-0.3 mm/rev, cutting speed $100 \mathrm{~m} / \mathrm{min}$, and depth of cut $2 \mathrm{~mm}$. The tests were carried out under dry conditions and with fluids based on mineral oils. Cutting forces were minimized when dry turning with lower feeds and higher cutting speeds. Uysal and Jawahir [10] studied the cutting forces and chip shaping when turning AISI 304 (X5CrNi18-10) stainless steel under dry machining conditions and using the minimum quantity lubrication (MQL)method with cutting speeds of 60-100 m/min. Compared to dry machining, lower cutting forces were observed with MQL conditions. A decrease in cutting forces was also observed with increasing cutting speed. The formation of serrated chips was clearly observed with the MQL conditions. Miyake et al. [11] tested chip breaking and cutting forces when machining AISI 304 (X5CrNi18-10) stainless steel under conventional and low frequency vibrationcutting (LFV) conditions with feeds of $0.005-0.06 \mathrm{~mm} / \mathrm{rev}$, a constant spindle speed of $3752 \mathrm{rpm}$, and cutting depth of $0.5 \mathrm{~mm}$. Regardless of the feed, the maximum cutting forces for LFV exceeded the cutting forces for conventional machining. The opposite was observed for the average values of the cutting forces. The cutting forces increased with increasing feed. Continuous chips and short chips occurred with traditional turning and LVF conditions, respectively. Fernandez-Abia et al. [12] studied cutting forces and chips geometry while turning AISI 303 (X8CrNiS18-9) steel in the range of cutting speeds $37-870 \mathrm{~m} / \mathrm{min}$, feed of $0.2 \mathrm{~mm} / \mathrm{rev}$, and depth of cut $1 \mathrm{~mm}$, under dry machining conditions. Above acutting speed of $450 \mathrm{~m} / \mathrm{min}$, a clear decrease in chip thickness has been noted and the cutting forces reach minimum values. Khanna et al. [13] analyzed changes of cutting forces and chip thickness ratio when turning 15-5 PH (X5CrNiCuNb15-5) stainless steel under dry, wet, MQL, and cryogenic conditions. Variable cutting speeds of $83-199 \mathrm{~m} / \mathrm{min}$, feeds of $0.111-0.333 \mathrm{~mm} / \mathrm{rev}$, and a constant depth of cut of $1 \mathrm{~mm}$ were used. Compared to cryogenic machining, an increase in the value of cutting forces of $29.26 \%$ for dry machining, $52.68 \%$ for wet machining, and $53.33 \%$ for MQL machining was noted at higher cutting speeds $(199 \mathrm{~m} / \mathrm{min})$ and feed $(0.333 \mathrm{~mm} / \mathrm{rev})$. Higher chip thickness ratios were observed under dry machining conditions compared to other methods.

Leksycki et al. [6] analyzed chip shaping when turning 17-4 PH (X5CrNiCuNb16-4) stainless steel. The processing was carried out under conditions of dry, wet, MQL, and MQL + EP (extreme pressure) machining in the range of cutting speed $150-500 \mathrm{~m} / \mathrm{min}$, feeds $0.05-0.4 \mathrm{~mm} / \mathrm{rev}$, and constant depth of cut $0.5 \mathrm{~mm}$. Short spiral chips under the machining conditions tested were observed at a cutting speed of $456 \mathrm{~m} / \mathrm{min}$ and a feed rate of $0.27 \mathrm{~mm} / \mathrm{rev}$. Wagner et al. [14] studied the effect of high-pressure coolant on the chip fragmentation of martensitic stainless steel. Cutting speeds of $50-110 \mathrm{~m} / \mathrm{min}$, uncut chip thickness $0.2-0.6 \mathrm{~mm}$, lubricant pressure 100-350 bars, and cutting depth 2-4 mm were analyzed. Regardless of the machining conditions, the pressure did not affect the chip type and shape, but only changed its rolling radius. Sivaiah and Chakradhar [15] studied the effect of cryogenic cooling on chip morphology while turning 17-4 PH (X5CrNiCuNb16-4) stainless steel and the results were compared to dry, wet, and MQL conditions. Cryogenic machining provides more favorable and lower chip thickness compared to other cooling methods.

Ning et al. [16] carried out experimental and modeling studies on cutting forces. Using iterative gradient search methods, they searched for stable parameters for the Johnson-Cook model that provided acceptable differences between predicted and experimental forces. The Johnson-Cook model used also took into account chip formation features, cooling conditions, and material properties. Close correlations between predicted and experimentally obtained forces were observed. Based on the 
Johnson-Cook model, Ning et al. [17] analyzed cutting forces with respect to cutting temperatures. Cutting forces were predicted using the extended chip formation model. The experimental results were similar to those obtained in the simulation.

One of the methods of analyzing the process of stainless steel machining is the finite element method (FEM). Korkmaz and Günay [18] performed FEM simulations of the turning of AISI 420 martensitic stainless steel, based on three different levels of cutting speed, depth of cut, and feed. The difference between the values of experimental and simulated cutting force and feed force was on average $4.24 \%$ and $9.7 \%$, respectively. Galanis and Manolakos [19] examined the FEM in predicting cutting forces when performing high speed turning of AISI 316L stainless steel. It was concluded that the values of cutting forces can be predicted by FEM software with high accuracy. Koyee et al. [20] presented a new methodology to inversely calculate the input parameters while simulating the machining of two different duplex stainless steels. After optimization of the friction coefficient, thermal contact conductance, etc., with special software, they were applied in a 3D-FEM simulation. It was shown that the optimization procedure allowed minimizing of the overall differences between the numerically obtained and experimentally measured cutting forces, tool nose temperature, and chip thickness at any specified cutting conditions.

In summary, there are many scientific studies that analyze cutting forces and chip shapes under different cooling conditions and cutting parameters when turning stainless steels. The interest of researchers indicates that this problem is very important and has not yet been fully described. However, there is only a small amount of research on the changes in the three components of total cutting force and chip shape when finish turning 17-4 PH stainless steel. In particular, there is no information that allows for comparing of the effect of dry, wet, and MQL machining conditions over a wide range of depths of cut and feeds using FEM modeling. The aim of the article was to study the changes of three components of total cutting force and chip shape when 17-4 PH stainless steel finish turning, depending on the depth of cut and feed under dry, wet, and MQL machining conditions.

\section{Materials and Methods}

The 17-4 PH (X5CrNiCuNb16-4) stainless steel was used as the material machined. This is precipitation hardening chromium-nickel stainless steel containing $\sim 3 \%$ copper. As was stated by Liu et al. [21], it is strengthened by the precipitation of copper-rich particles from the metal matrix. According to DIN EN 10088-1:2014-12, the material has an elastic modulus of 195 GPA, a tensile strength of 930-1100 MPa, and a yield strength of $720 \mathrm{MPa}$.

A cutter with a CoroTurn SDJCR 2525M 11 (SandvikCoromant, Sandviken, Sweden) tool holder and a CoroTurn DCMX 11 T3 04-WM 1115 (SandvikCoromant, Sandviken, Sweden) insert wasused. Variable feeds of $0.05-0.4 \mathrm{~mm} / \mathrm{rev}$ and depths of cut of $0.2-1.2 \mathrm{~mm}$ with a constant cutting speed of $220 \mathrm{~m} / \mathrm{min}$ were applied.

The research was carried out under dry, wet, and MQL cutting conditions, because there is a growing need for not only technical but also ecological processing nowadays [22]. CheHaron et al. [23] concluded that dry processing is popular in production to reduce costs. However, as Ortega et al. [24] and Egea et al. [25] noted, dry machining affects tool life significantly. In turn, Nouari and Ginting [26] found that dry processing provides economic and environmental benefits. When wet machining, Maruda et al. [27] determined that cutting fluid based on machining oils reduces the temperature occurring in the cutting zone.

In this research, a water emulsion based on the machining emulsifying oil, Castrol Alusol SL 51 $\mathrm{XBB}$, with working concentration of $7 \%$ was used as a cutting fluid. In the MQL method, FUCHS ECOCUT MIKRO $20 \mathrm{E}$ oil was used, which was mixed with air and prepared as amist with the Lenox 1LN Micronizer (Lenox, East Longmeadow, MA, USA). Constant preparing parameters were used, namely air flow of $5.8 \mathrm{~L} / \mathrm{m}$, oil flow of $39.4 \mathrm{~mL} / \mathrm{h}$, constant pressure of 70 Parameter Space Investigation (PSI) (0.48 MPa), and distance between nozzle and work-piece contact point of $0.2 \mathrm{~m}$. According to Maruda et al. [28], such conditions of oil mist formation ensure favorable conditions. 
Krolczyk et al. [29] found that the MQL method plays an important role in the approach to sustainable and clean production.

Samples were machined using a CU502 universal lathe (ZMM, Sofia, Bulgaria). The measurements of the three components of total cutting force (cutting $F_{\mathrm{c}}$, feed $F_{\mathrm{f}}$, and passive $F_{\mathrm{p}}$ ) were carried out using a 9129A piezoelectric dynamometer from Kistler (Kistler Group, Winterthur, Switzerland). Processing, visualization, and recording of signals were carried out using Dyno Ware software (Kistler Group, Winterthur, Switzerland).

The cutting force $F_{\mathrm{c}}$ and the feed force $F_{\mathrm{f}}$ were also calculated by Finite Element Method (FEM) for orthogonal turning of steel tested under wet cutting conditions. The computer simulation was performed using DEFORM 2D/3D software 12 (Scientific Forming Technologies Corporation, Columbus, $\mathrm{OH}, \mathrm{USA}$ ) developed by Taylan Altan, Goverdhan D. Lahoti, and Soo Ik Oh. The Johnson-Cook constitutive model was used, which was effectively used for modeling the cutting forces of turning process [30].

The design of experiments was developed on the basis of the PSI method [31]. The 7 test points made it possible to perform statistical calculations, which were carried out using Statistica-13 software. The PSI method has been described in detail in [6].

The conceptual scheme and methodology of research are presented in Figure 1.

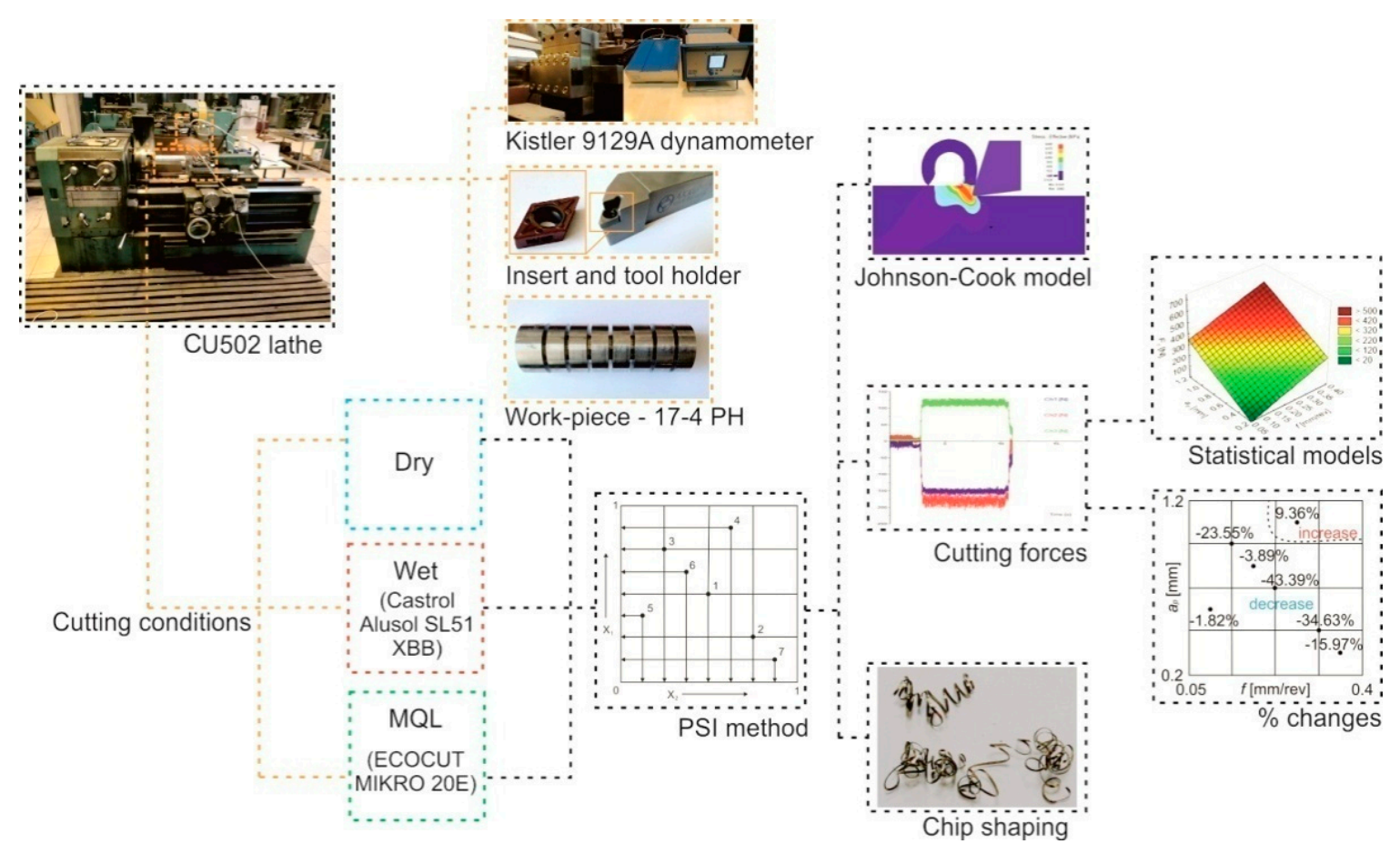

Figure 1. The conceptual scheme and research methodology.

\section{Results and Discussion}

\subsection{Statistical Models of Cutting Forces}

The statistical models for calculating the components of the cutting forces, depending on the depth of cut and feed, are presented in Table 1. 
Table 1. Statistical models for calculating the cutting forces $F_{\mathrm{c}}, F_{\mathrm{f}}$, and $F_{\mathrm{p}}$ when turning 17-4 PH stainless steel under dry, wet, and minimum quantity lubrication (MQL) cooling conditions.

\begin{tabular}{c}
\hline Dry Terms \\
\hline$F_{\mathrm{c}}=-117.27+999.94 f+359.51 a_{p}$ \\
$F_{\mathrm{f}}=58.04+159.24 f+182.75 a_{p}$ \\
$F_{\mathrm{p}}=74.82+304.21 f-17.11 a_{p}$ \\
\hline Wet Terms \\
\hline$F_{\mathrm{c}}=-100.45+690.46 f+313.27 a_{p}$ \\
$F_{\mathrm{f}}=-35.88+103.19 f+192.73 a_{p}$ \\
$F_{\mathrm{p}}=30.06+189.93 f+14.82 a_{p}$ \\
\hline MQL Terms \\
\hline$F_{\mathrm{c}}=-108.19+708.15 f+347.71 a_{p}$ \\
$F_{\mathrm{f}}=-20.93+84.03 f+205.11 a_{p}$ \\
$F_{\mathrm{p}}=39.34+206.11 f+12.33 a_{p}$ \\
\hline
\end{tabular}

The dependences of cutting force $F_{\mathrm{c}}$, feed force $F_{\mathrm{f}}$, and passive force $F_{\mathrm{p}}$ on the depth of cut and feed in dry, wet, and MQL cooling conditions are shown in Figures 2-4.
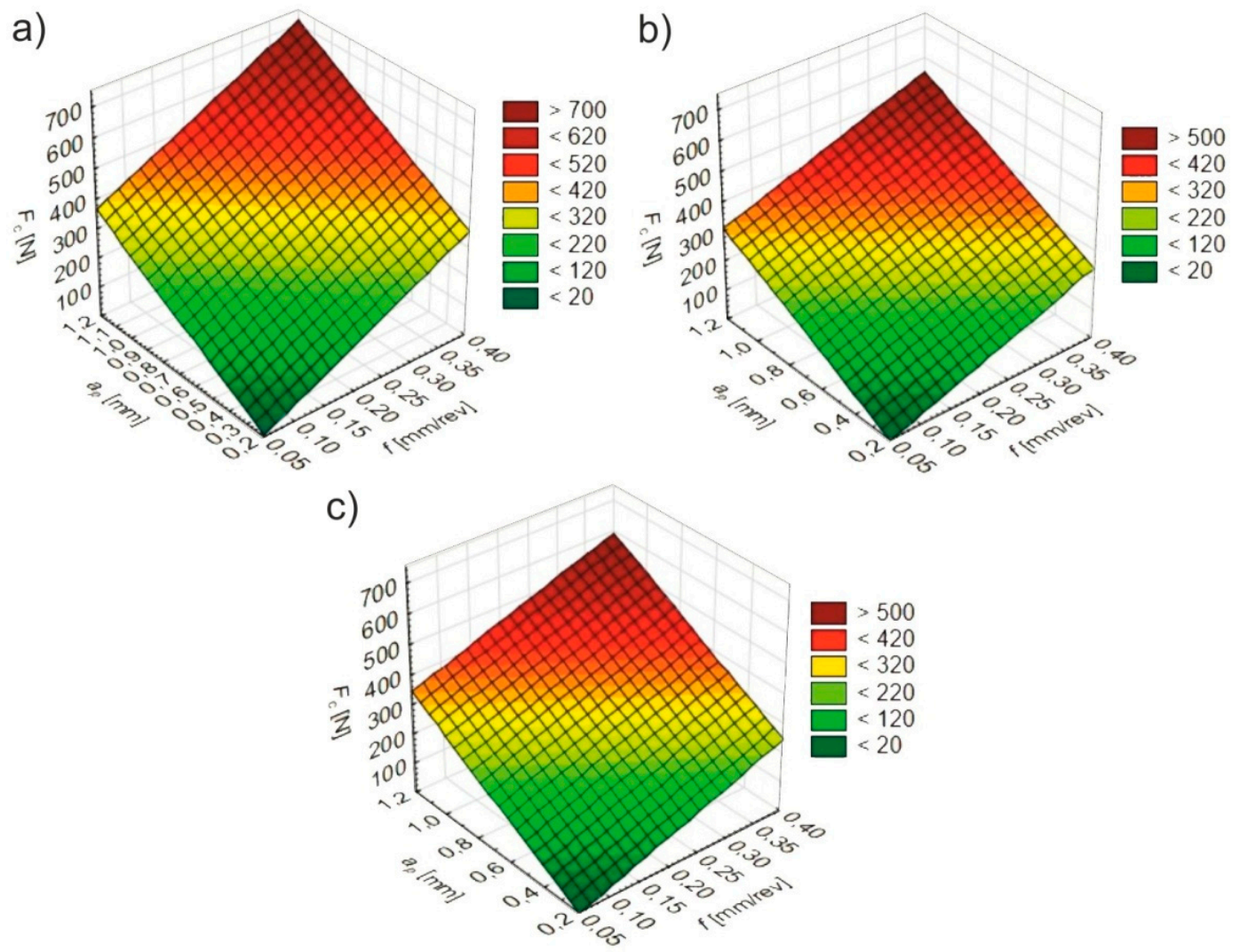

Figure 2. Changes in the cutting force $\mathrm{F}_{\mathrm{c}}$ depending on the depth of cut and feed under (a) dry; (b) wet; (c) MQL machining conditions. 
a)

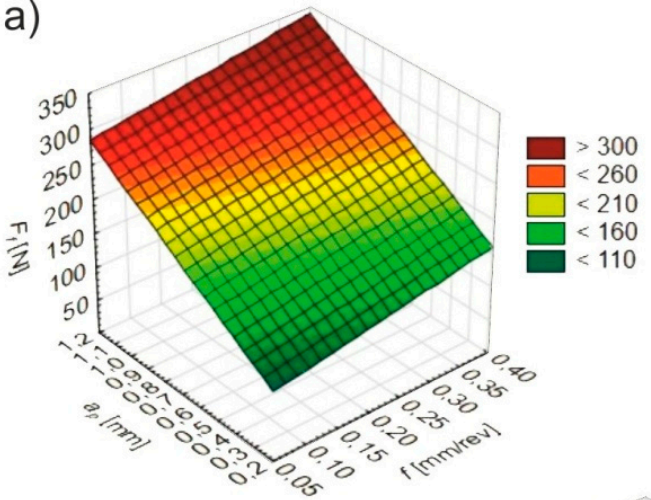

b)

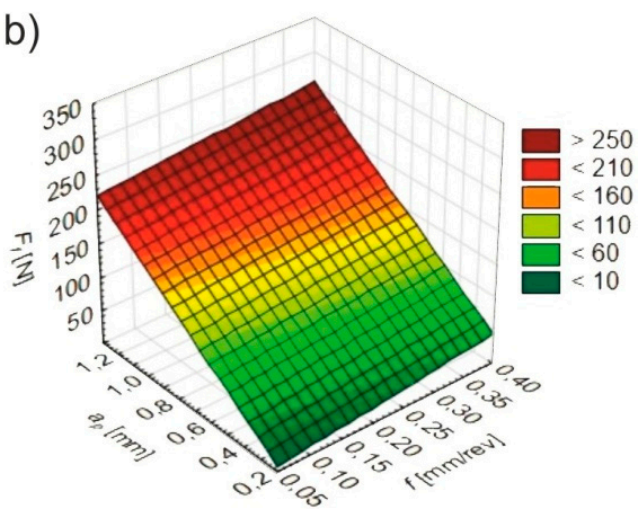

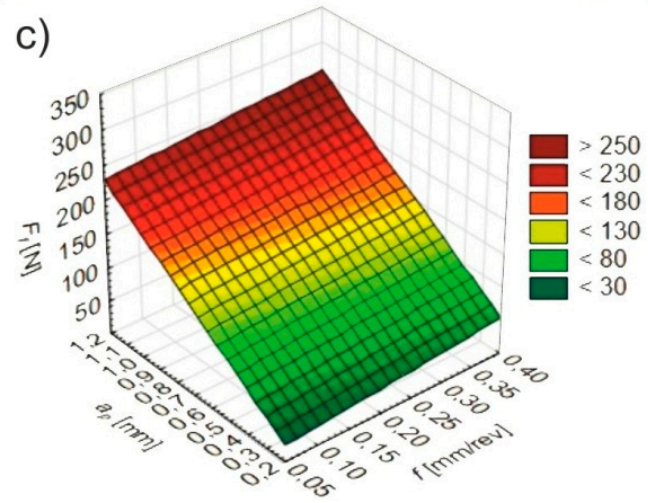

Figure 3. Changes in the feed force $F_{\mathrm{f}}$ depending on the depth of cut and feed under (a) dry; (b) wet; (c) MQL machining conditions.

a)

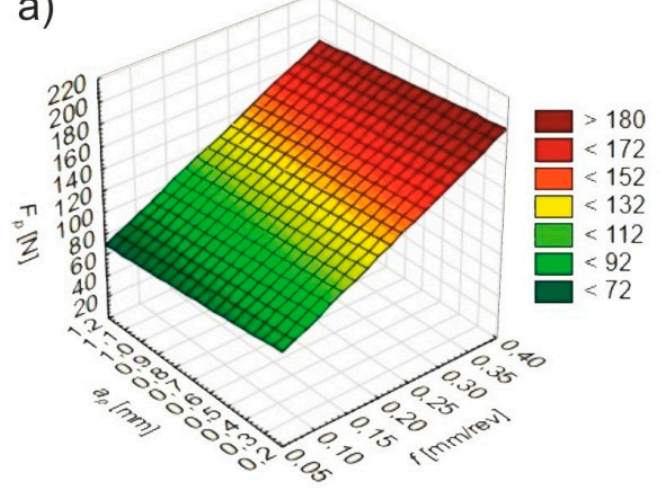

b)

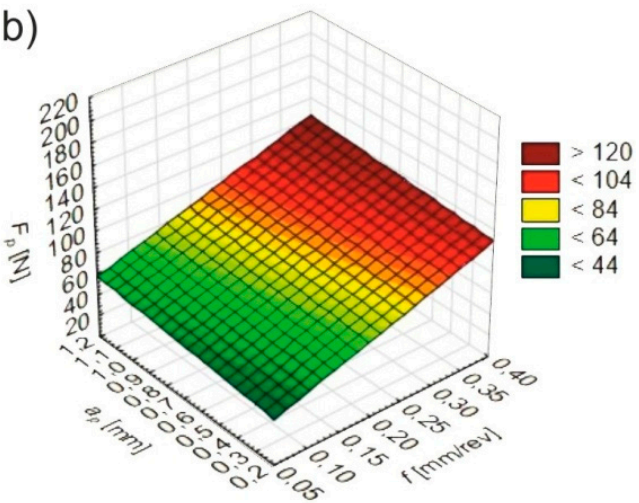

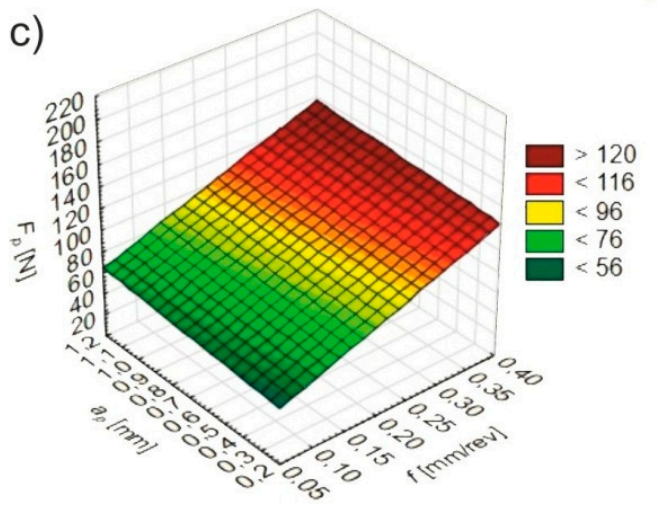

Figure 4. Changes in the passive force $F_{\mathrm{p}}$ depending on the depth of cut and feed under (a) dry; (b) wet; (c) MQL machining conditions. 
When machining 17-4 PH stainless steel under the considered conditions, lower values of the cutting force were observed in the range of lower cutting depths and feeds. Smaller feed force values were obtained in the range of lower cutting depths and feeds. Smaller values of passive cutting force were obtained for smaller feeds in the studied range of depths of cut. Krolczyk et al. [9] noted that the passive force plays an important role in forming the dimensional and shape accuracy of the work-piece. On the basis of Figures 2-4, it can also be concluded that in comparison to dry machining, wet and MQL machining provide smaller values for the cutting, feed, and passive forces. The same conclusions were made by Uysal and Jawahir [10].

\subsection{Percentage Changes of Cutting Forces}

The average percentage changes of the cutting, feed, and passive forces obtained in 7 PSI test points under wet machining conditions and using the MQL method compared to dry cutting conditions, depending on the depth of cut and feed, are shown in Figures 5-7.

a)

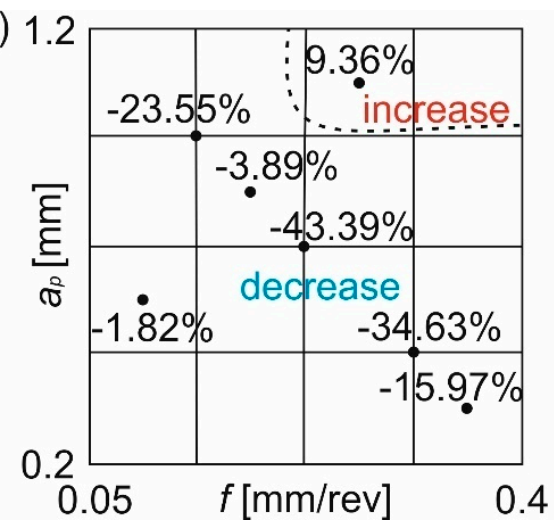

b)

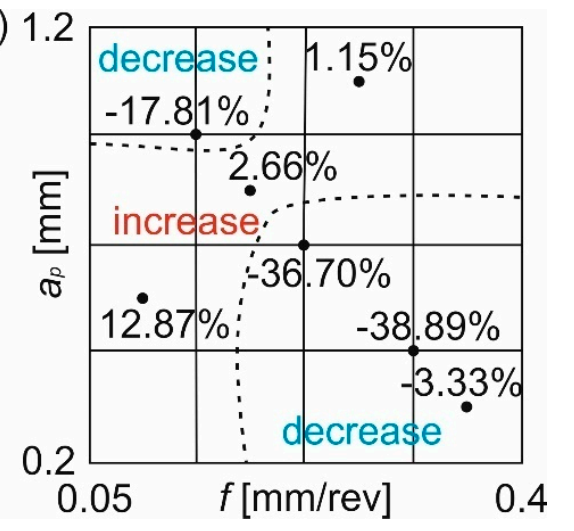

Figure 5. Percentage changes of the cutting force $F_{\mathrm{c}}$ under (a) wet and (b) MQL cooling conditions compared to dry machining.

a)

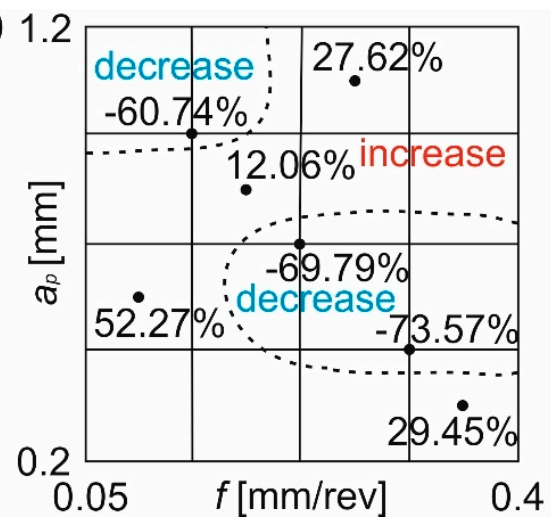

b) 1.2

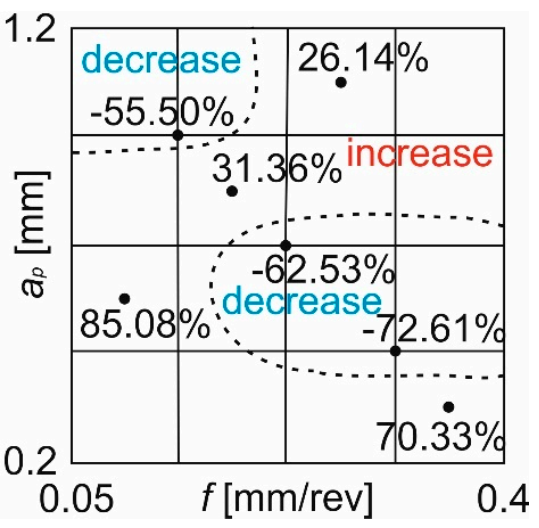

Figure 6. Percentage changes of the feed force $F_{\mathrm{f}}$ under (a) wet and (b) MQL cooling conditions compared to dry machining. 
a)

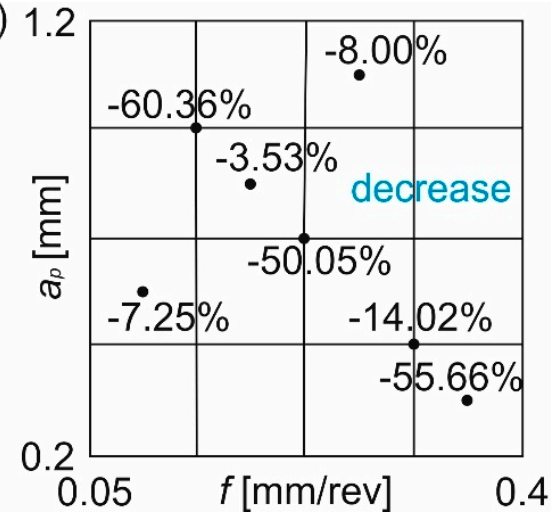

b) 1.2

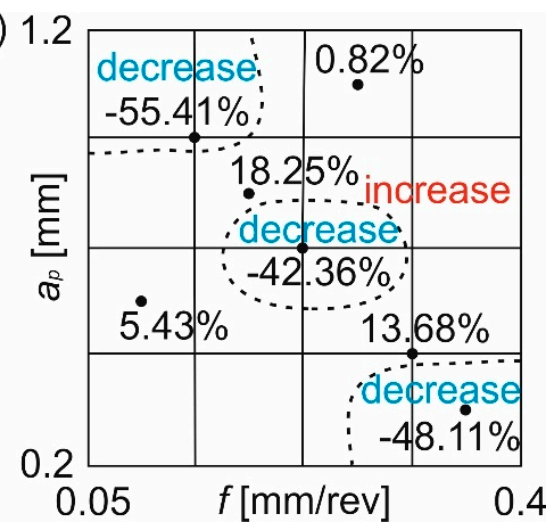

Figure 7. Percentage changes of the passive force $F_{\mathrm{p}}$ under (a) wet and (b) MQL cooling conditions compared to dry machining.

Compared to dry machining, the cutting force decreases in the range of $\sim 2-43 \%$ or increases by $\sim 9 \%$ when wet turning; it decreases in the range of $\sim 3-39 \%$ or increases by $1-13 \%$ while MQL turning. The increase in the cutting force is noted only in point 4 of the PSI matrix $\left(a_{p}=1.1 \mathrm{~mm}\right.$ and $f=0.27 \mathrm{~mm} / \mathrm{rev}$ ). When wet cutting compared to dry cutting, the feed force decreases by $\sim 61-73 \%$ or increases by $\sim 12-52 \%$ and in the presence of MQL, it decreases by $55-72 \%$ or increase by $26-85 \%$. In both cases, a significant reduction in the feed force rate occurs at points 1 ( $a_{p}=0.7 \mathrm{~mm}$ and $f=0.22 \mathrm{~mm} / \mathrm{rev}), 2\left(a_{p}=0.45 \mathrm{~mm}\right.$ and $\left.f=0.31 \mathrm{~mm} / \mathrm{rev}\right)$, and $3\left(a_{p}=0.95 \mathrm{~mm}\right.$ and $\left.f=0.14 \mathrm{~mm} / \mathrm{rev}\right)$. Compared to the conditions of dry machining, wet turning ensures a decrease in the value of the passive force in the range of cutting depths and feeds examined by 3-60\%, while when MQL machining, it decreases by $\sim 42-55 \%$ or increases to $\sim 18 \%$.

The build-up edge appears at the tool-chip contact area when turning stainless steels. Jemielniak [32] described that the build-up edge increases the rake angle and shortens the seizure zone and the total length of chip contact with the rake face, thus, reducing cutting forces. However, Ahmed et al. [33] revealed that the build-up edge can increase the nose radius of the cutting tool and cutting forces.

\subsection{Chip Shaping}

The chip shapes of 17-4 PH stainless steel obtained when finish turning in PSI test points, under dry, wet, and MQL conditions, are shown in Figure 8.

When turning with $a_{p}=1.07 \mathrm{~mm}$ and $f=0.27 \mathrm{~mm} / \mathrm{rev}$ in the cutting conditions considered, loose curved chips were registered which are beneficial and, as Maruda et al. [27] indicated, allow easy removal from the machining zone. When turning with $a_{p}=0.45 \mathrm{~mm}$ and $f=0.31 \mathrm{~mm} / \mathrm{rev}$ and $a_{p}=0.35 \mathrm{~mm}$ and $f=0.36 \mathrm{~mm} / \mathrm{rev}$, regardless of cooling conditions, open short and long spiral chips were registered. When turning with $a_{p}=0.7 \mathrm{~mm}$ and $f=0.22 \mathrm{~mm} / \mathrm{rev}$ under dry cutting conditions, open short screw chips were observed; under wet and MQL conditions, short ribbon chips appeared. When turning with $a_{p}=0.95 \mathrm{~mm}$ and $f=0.14 \mathrm{~mm} / \mathrm{rev}$ under dry cutting conditions, open short screw chips were noted, while under wet cooling conditions and using the MQL method, open tangled screw chips were observed, which are unfavorable and, according to Michailidis [34], may leave traces on the machined surface. When turning with $a_{p}=0.57 \mathrm{~mm}$ and $f=0.09 \mathrm{~mm} / \mathrm{rev}$ and $a_{p}=0.82 \mathrm{~mm}$ and $f=0.18 \mathrm{~mm} / \mathrm{rev}$ under dry cutting conditions, long ribbon chips were recorded; under wet cooling, tangled ribbon chips appeared; under MQL conditions, short ribbon chips were registered.

It should be mentioned that besides the depth of cut and feed, the cooling conditions also affect chip shapes when turning the steel tested. Clear differences are observed between dry machining, wet cooling, and the MQL method. More favorable chip shapes are observed under dry machining conditions. 


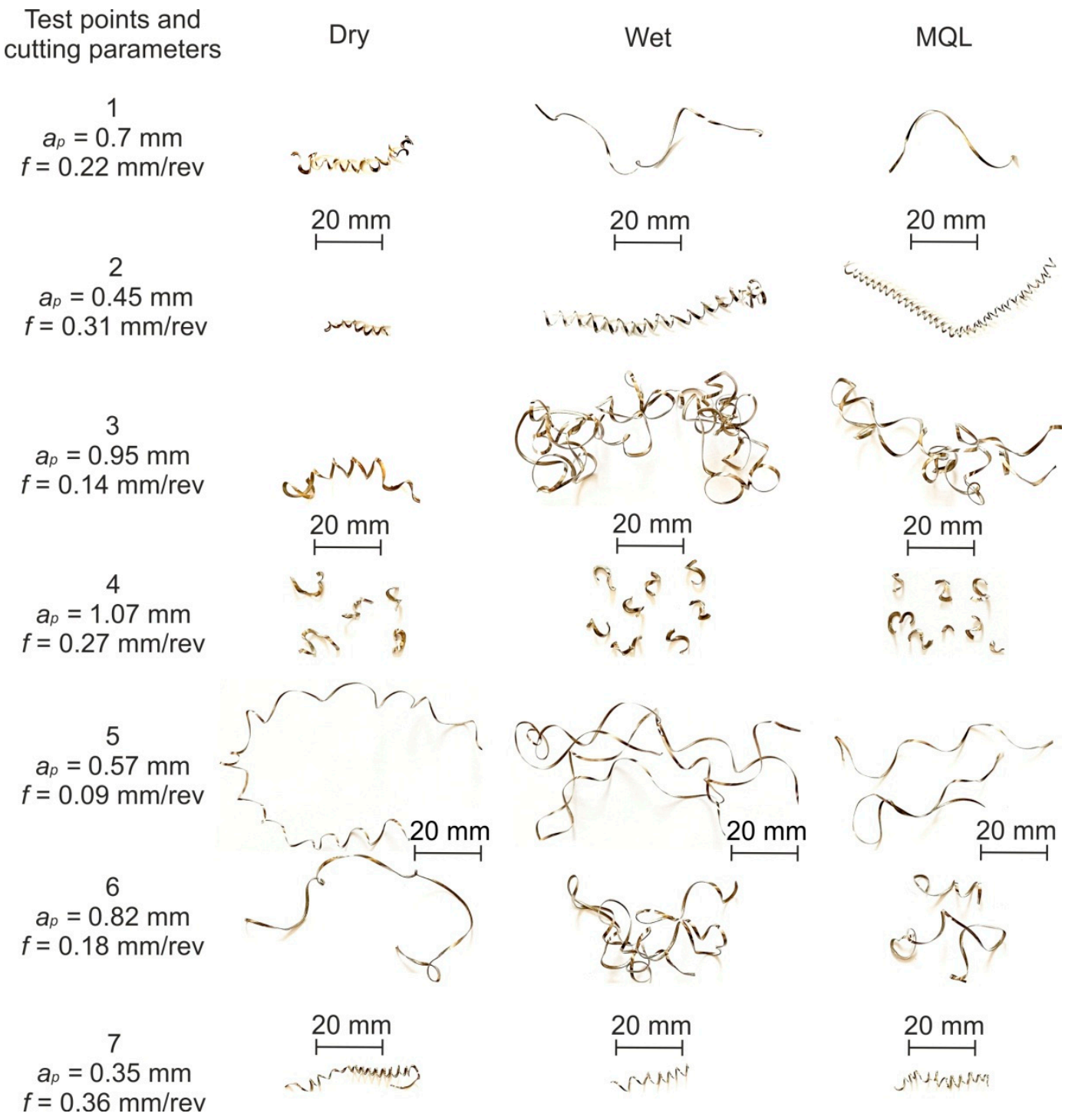

Figure 8. Chip shapes when finish turning the steel tested.

\subsection{FEM Modeling and Its Results}

The material constitutive model used to simulate the machining process was the Johnson-Cook model, which can be determined using the equation for the equivalent stress:

$$
\bar{\sigma}_{J C}=\left[A+B(\bar{\varepsilon})^{n}\right] \cdot\left[1+C \ln \left(\dot{\bar{\varepsilon}} / \dot{\bar{\varepsilon}}_{0}\right)\right] \cdot\left[1-\left(\frac{T_{w}-T_{0}}{T_{m}-T_{0}}\right)^{m}\right]
$$

where: $\bar{\sigma}_{J C}$-Johnson-Cook plastic equivalent stress (MPa); $A$-Initial yield stress (MPa); $B$ - Hardening modulus(MPa); $C$-Strain rate dependency coefficient (MPa); $m$-Thermal softening coefficient; $n$-Work-hardening exponent; $T_{w}$-Work-piece computed temperature $\left({ }^{\circ} \mathrm{C}\right) ; T_{m}$-Melting temperature $\left({ }^{\circ} \mathrm{C}\right) ; T_{0}$-Reference temperature $\left({ }^{\circ} \mathrm{C}\right) ; \bar{\varepsilon}$-Plastic strain; $\dot{\bar{\varepsilon}}$-Equivalent plastic strain rate $\left(\mathrm{s}^{-1}\right)$; $\dot{\bar{\varepsilon}}_{0}$-Reference plastic strain rate $\left(\mathrm{s}^{-1}\right)$.

The values of $A, B, n, C$, and $m$ coefficients for the stainless steel 17-4 PH were taken from the literature [35] and are presented in Table 2 . In order to determine the coefficient of friction $\mu$, preliminary simulations in the range $\mu=0.08-1.0$ were carried out. The results closest to the experimental ones were obtained for $\mu=0.58$. The reference temperature and the reference plastic strain rate were accepted as $20{ }^{\circ} \mathrm{C}$ and $0.001 \mathrm{~s}^{-1}$, respectively. 
Table 2. Johnson-Cook model coefficients for 17-4 PH stainless steel (data from [35]).

\begin{tabular}{cccccc}
\hline Material & $\boldsymbol{A}(\mathbf{M P a})$ & $\boldsymbol{B}(\mathbf{M P a})$ & $\boldsymbol{n}$ & $\boldsymbol{C}$ & $\boldsymbol{m}$ \\
\hline $17-4 \mathrm{PH}$ & 1279 & 630 & 0.64 & 0.02 & 0.56 \\
\hline
\end{tabular}

The results of the simulation performed in DEFORM 2D/3D software 12 (Scientific Forming Technologies Corporation, Columbus, OH, USA) for PSI point No. $1\left(a_{p}=0.7 \mathrm{~mm}, f=0.22 \mathrm{~mm} / \mathrm{rev}\right)$ and $\mu=0.58$ are shown in Figure 9 .

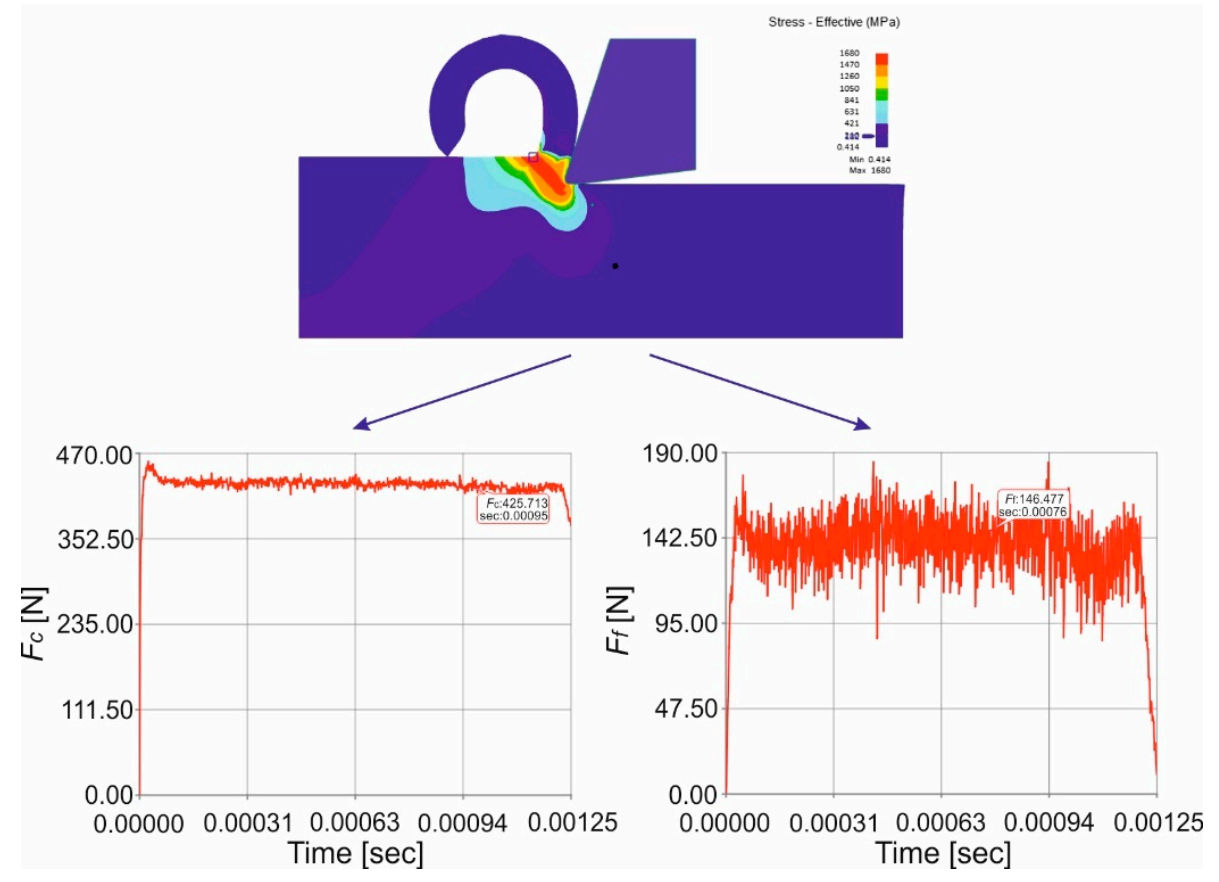

Figure 9. Results of Finite Element Method (FEM) simulation for $a_{p}=0.7 \mathrm{~mm}, f=0.22 \mathrm{~mm} / \mathrm{rev}$ and $\mu=$ 0.58 .

The formulas for calculating the cutting force $F_{\mathrm{c}}$ and the feed force $F_{\mathrm{f}}$ depending on the depth of cut and feed under wet cooling, determined from the experimental studies and FEM modeling, are presented in Table 3.

Table 3. Formulas for calculating the cutting forces depending on the depth of cut and feed, under wet cooling conditions.

\begin{tabular}{cc}
\hline Statistical Models & FEM Simulation \\
\hline$F_{\mathrm{c}}=-100.45+690.46 f+313.27 a_{p}$ & $F_{\mathrm{c}}=-100.15+692.44 f+304.84 a_{p}$ \\
$F_{\mathrm{f}}=-35.88+103.19 f+192.73 a_{p}$ & $F_{\mathrm{f}}=19.83-80.15 f+133.57 a_{p}$ \\
\hline
\end{tabular}

Analyzing the mathematical models obtained for experimental research and the FEM simulation, it can be seen that the feed and depth of cut affect the value of the cutting force $F_{\mathrm{c}}$ with almost identical results. For the feed force $F_{\mathrm{f}}$, the models are different.

The dependences of the cutting force $F_{\mathrm{c}}$ and the feed force $F_{\mathrm{f}}$ on the depth of cut and feed under wet cooling conditions, obtained for experimental research and the FEM simulation, are shown in Figures 10 and 11. 
a)

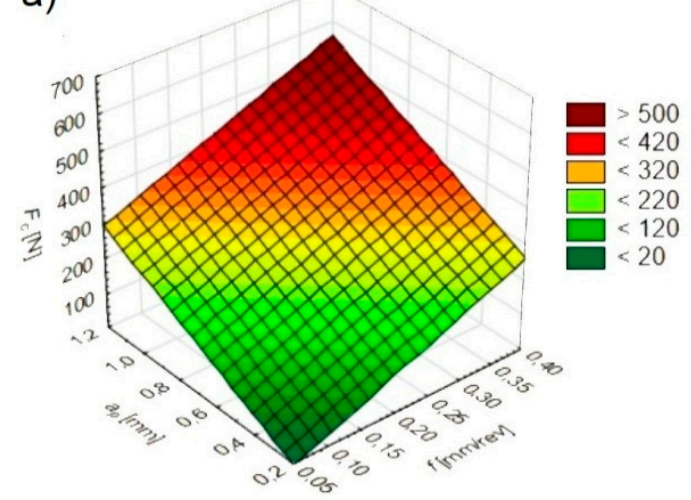

b)

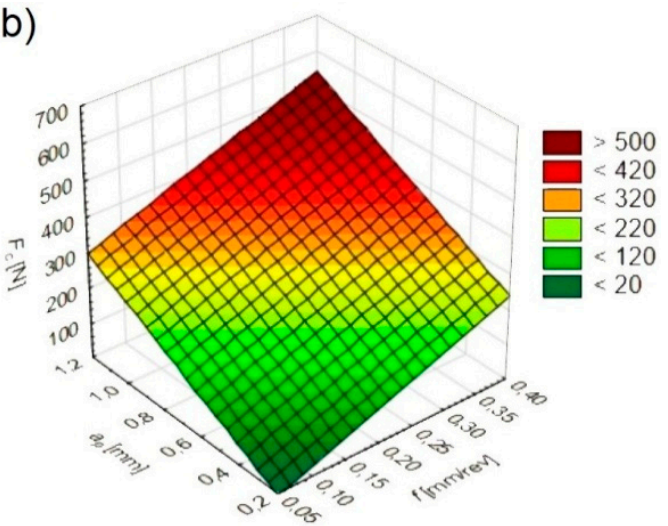

Figure 10. Changes in cutting force $F_{\mathrm{c}}$ according to the depth of cut and feed under wet conditions: (a) experimental research; (b) FEM simulation.

a)

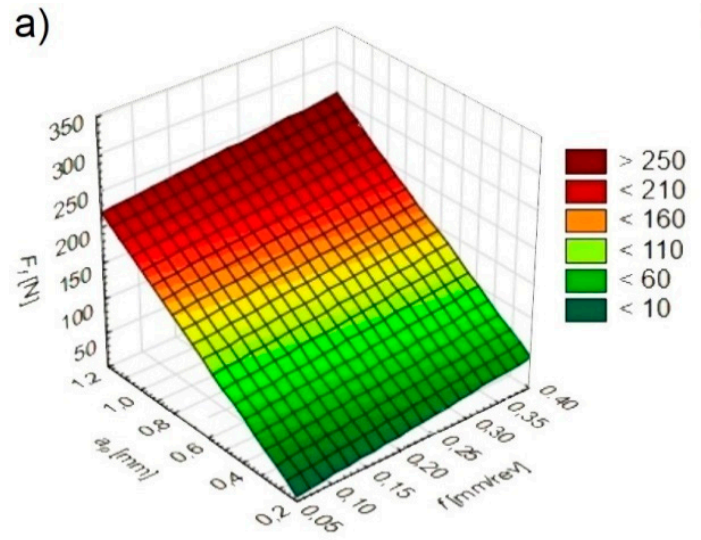

b)

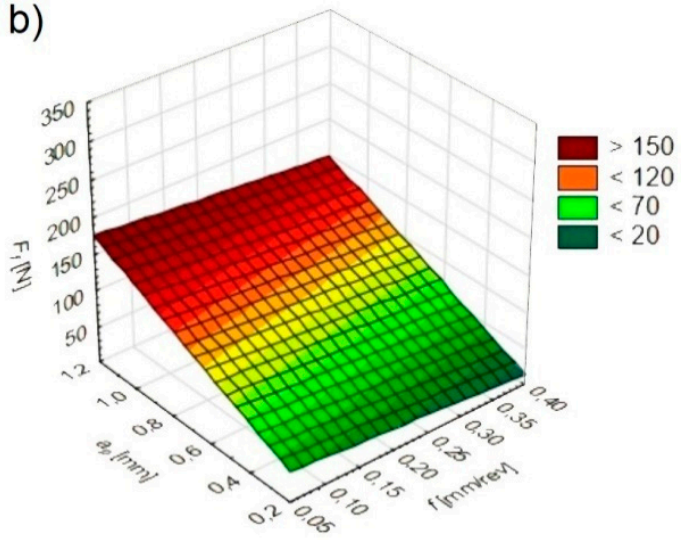

Figure 11. Changes in feed force $F_{\mathrm{f}}$ according to the depth of cut and feed under wet conditions: (a) experimental research; (b) FEM simulation.

Analyzing the graphs presented above, it can be concluded that the directions of change of the cutting force $F_{\mathrm{c}}$ for both the experimental research and the FEM simulation are identical. For the feed force $F_{\mathrm{f}}$, the directions of change are different. Clear differences are observed as the depth of cut increases.

The percentage changes of the cutting force $F_{\mathrm{c}}$ and feed force $F_{\mathrm{f}}$ values obtained in the experimental research and FEM simulation are shown in Figures 12 and 13. 


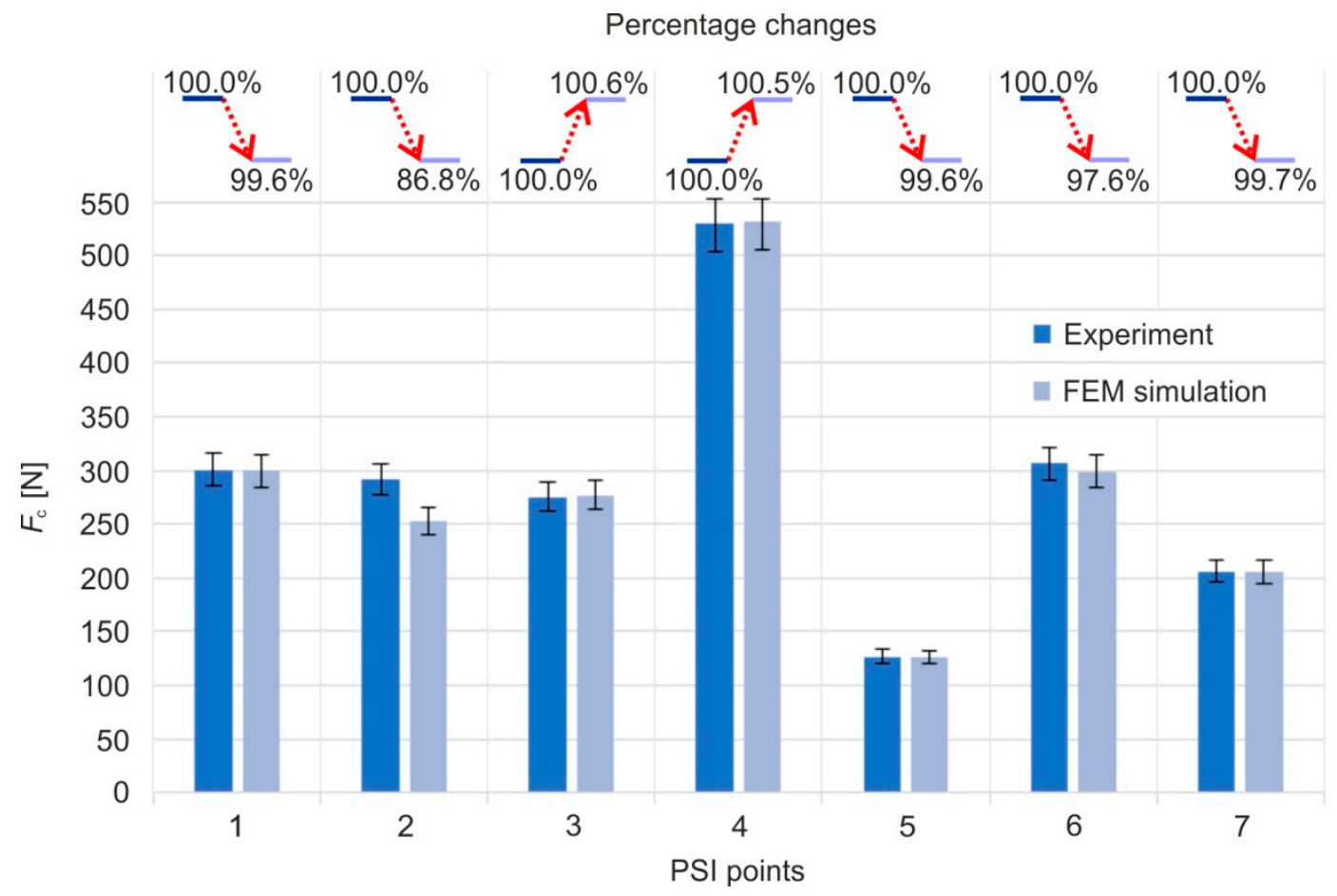

Figure 12. Percentage changes of the cutting force $F_{\mathrm{c}}$ between experimental research and FEM simulation obtained in 7 points according to the Parameter Space Investigation (PSI) method.

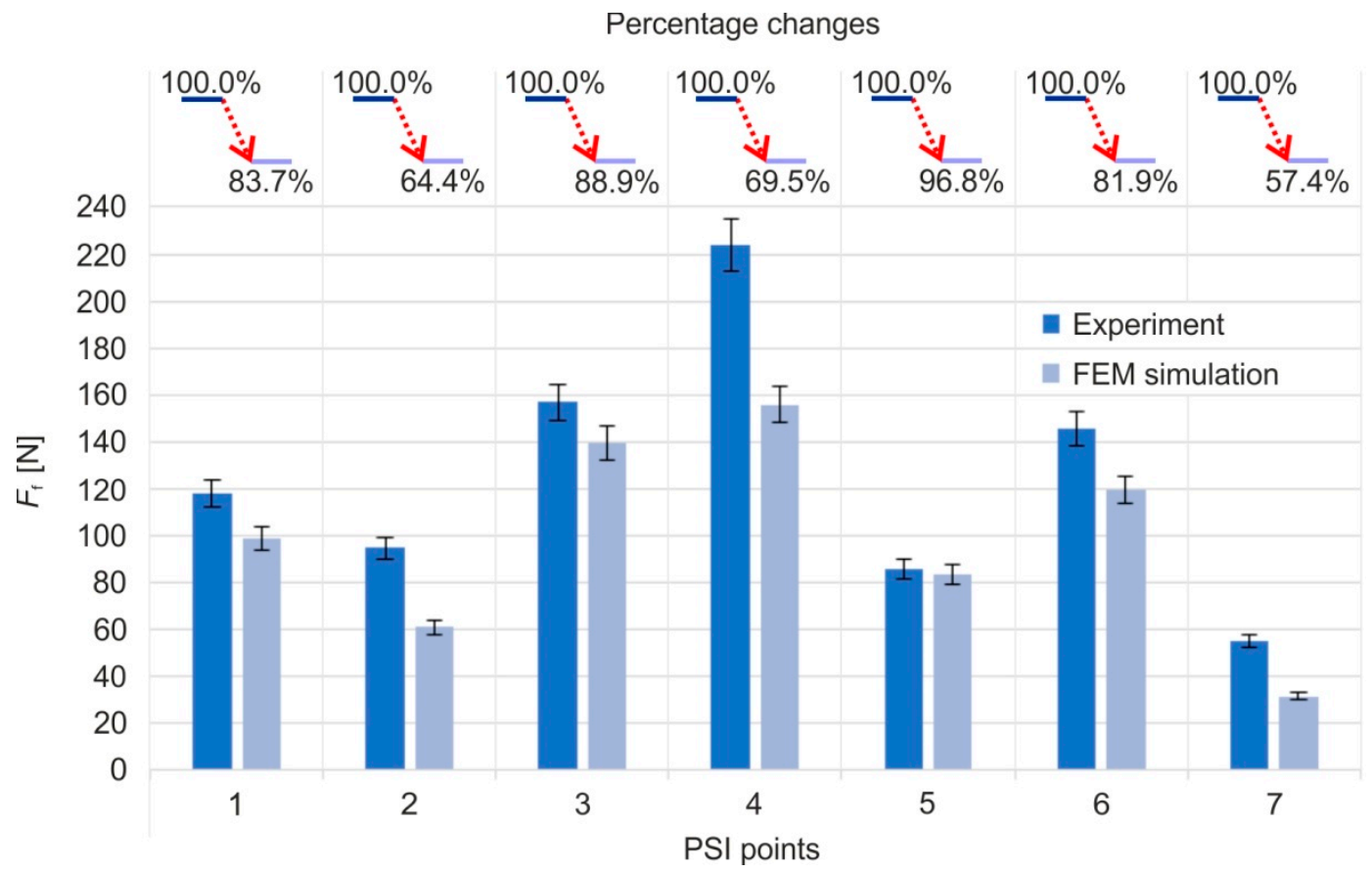

Figure 13. Percentage changes of the feed force $F_{\mathrm{f}}$ between experimental research and FEM simulation obtained in 7 points according to the PSI method.

For the cutting force $F_{c}$, the biggest difference of up to $13.2 \%$ between the experimental tests and the FEM simulation is observed at PSI point 2. At the other test points, changes do not exceed $2.4 \%$. For the feed force $F_{\mathrm{f}}$, significant differences of up to $35.6 \%$ can be observed. This is due to the effect of nose radius and radius of cutting edge rounding on the $F_{\mathrm{f}}$ force, which cannot be taken into account in the 2D FEM modeling. 


\section{Conclusions}

In this paper, the changes of three components of total cutting force and chip shape when finish turning 17-4 PH stainless steel, depending on the depth of cut $0.2-1.2 \mathrm{~mm}$ and feed $0.05-0.4 \mathrm{~mm} / \mathrm{rev}$ under dry, wet, and MQL methods, were analyzed. The FEM simulation of changes in cutting forces was carried out with the Johnson-Cook constitutive model. On the basis of the obtained results, it was determined that:

1. The cutting force $F_{\mathrm{c}}$ and feed force $F_{\mathrm{f}}$ depend on the depth of cut and the feed, while the passive force $F_{\mathrm{p}}$ is primarily determined by the feed value.

2. Regardless of the cooling conditions, lower cutting forces are reached for lower cutting depths and feeds. Therefore, in order to minimize the cutting forces, it is recommended to reduce the depth of cut and at the same time, use smaller feeds.

3. Compared to dry machining, wet cooling conditions resulted in a reduction in the cutting force of $\sim 43 \%$, feed force of $\sim 73 \%$, and passive force of $\sim 60 \%$, while with MQL conditions of $\sim 39 \%, \sim 72 \%$, and $\sim 55 \%$ respectively.

4. When turning with $a_{p}=1.0-1.1 \mathrm{~mm}$ and $f=0.25-0.3 \mathrm{~mm} / \mathrm{rev}$ under dry, wet, and MQL machining, favorable chip shapes, i.e., loose curves, were observed; it is recommended to use parameters in the ranges mentioned above. Unfavorable chip shapes, i.e., open screw, tangled, long ribbon, and long tangled, were registered in the ranges $a_{p}=0.5-0.1 \mathrm{~mm}$ and $f=0.05-0.2 \mathrm{~mm} / \mathrm{rev}$. Compared to wet MQL cooling conditions, more favorable chip shapes were recorded under dry processing.

5. Compared to the experimental research, the FEM simulation for the cutting force $F_{\mathrm{c}}$ showed almost identical mathematical models and minimal differences depending on the machining parameters at the PSI tested points, which reached to $\sim 13 \%$. For the feed force $F_{\mathrm{f}}$, larger discrepancies were obtained, up to $\sim 36 \%$, due to the unaccounted effect of the nose radius and radius of cutting-edge rounding. It is concluded that the modeling of cutting forces of 17-4 PH stainless steel should be further developed and experimental research works are still desirable.

6. The main novelty of the work is the detailed analysis of the three components of the total cutting force and chip shape when finish turning new 17-4 PH stainless steel under different cooling conditions and a wide range of cutting parameters that allow their direct comparison. The results obtained can be successfully used in scientific modeling research as well as in industrial practice.

Author Contributions: Conceptualization, K.L.; methodology, K.L. and J.L.; software, K.L.; formal analysis, K.L. and E.F.; investigation, K.L. and E.F.; modeling, J.L.; data curation, K.L., R.C. and R.M.; writing-original draft preparation, K.L.; writing-review and editing, K.L., E.F. and R.C.; visualization, K.L. and J.L.; supervision, E.F. All authors have read and agreed to the published version of the manuscript.

Funding: The authors gratefully acknowledge the financial support from the program of the Polish Ministryof Science and Higher Education under the name "Regional Initiative of Excellence" in 2019-2022, project no. 003/RID/2018/19, funding amount 11936596.10 PLN".

Conflicts of Interest: The authors declare no conflict of interest.

\section{References}

1. Ahlhelm, M.; Günther, P.; Scheithauer, U.; Schwarzer, E.; Günther, A.; Slawik, T.; Moritz, T.; Michaelis, A. Innovative and novel manufacturing methods of ceramics and metal ceramic composites for biomedical applications. J. Eur. Ceram. Soc. 2016, 36, 2883-2888. [CrossRef]

2. Mutlu, I.; Oktay, E. Characterization of $17-4 \mathrm{PH}$ stainless steel foam for biomedical applications in simulated body fluid and artificial saliva environments. Mat. Sci. Eng. C 2013, 33, 1125-1131. [CrossRef] [PubMed]

3. Gunjal, S.U.; Patil, N.G. Experimental Investigations into Turning of Hardened AISI 4340 Steel using Vegetable based Cutting Fluids under Minimum Quantity Lubrication. Procedia Manuf. 2018, 20, 18-23. [CrossRef]

4. Li, B.; Wang, X.; Hu, Y.; Li, C. Analytical prediction of cutting forces in orthogonal cutting using unequal division shear-zone model. Int. J. Adv. Manuf. Technol. 2011, 54, 431-443. [CrossRef] 
5. Leksycki, K.; Feldshtein, E. On the analysis chip shaping after finishing turning of Ti6Al4V titanium alloy under dry, wet and MQL conditions. Arch. Mech. Technol. Mater. 2019, 39, 36-40. [CrossRef]

6. Leksycki, K.; Feldshtein, E.; Królczyk, G.M.; Legutko, S. On the Chip Shaping and Surface Topography when Finish Cutting 17-4 PH Precipitation-Hardening Stainless Steel under Near-Dry Cutting Conditions. Materials 2020, 13, 2188. [CrossRef]

7. Litak, G.; Polyakov, Y.; Timashev, S.F.; Rusinek, R. Dynamics of stainless steel turning: Analysis by flicker-noise spectroscopy. Physica A 2013, 392, 6052-6063. [CrossRef]

8. Selvaraj, D.P.; Chandramohan, P.; Mohanraj, M. Optimization of surface roughness, cutting force and tool wear of nitrogen alloyed duplex stainless steel in a dry turning process using Taguchi method. Measurement 2014, 49, 205-215. [CrossRef]

9. Krolczyk, G.M.; Nieslony, P.; Maruda, R.W.; Wojciechowski, S. Dry cutting effect in turning of duplex stainless steel as a key factor in clean production. J. Clean. Prod. 2017, 142, 3343-3354. [CrossRef]

10. Uysal, A.; Jawahir, I.S. Validation of the slip-line model for serrated chip formation in orthogonal turning under dry and MQL conditions. Procedia CIRP 2019, 82, 124-129. [CrossRef]

11. Miyake, A.; Kitakaze, A.; Katoh, S.; Muramatsu, M.; Noguchi, K.; Sannomiya, K.; Nakaya, T.; Sasahara, H. Chip control in turning with synchronization of spindle rotation and feed motion vibration. Precis. Eng. 2018, 53, 38-45. [CrossRef]

12. Fernandez-Abia, A.I.; Barreiro, J.; Lopez de Lacalle, L.N.; Martinez, S. Effect of very high cutting speeds on shearing, cutting forces and roughness in dry turning of austenitic stainless steels. Int. J. Adv. Manuf. Technol. 2011, 57, 61-71. [CrossRef]

13. Khanna, N.; Shah, P.; Maruda, R.W.; Krolczyk, G.M.; Hegab, H. Experimental investigation and sustainability assessment to evaluate environmentally clean machining of 15-5 PH stainless steel. J. Manuf. Process. 2020, 56, 1027-1038. [CrossRef]

14. Wagner, V.; Faye, J.P.; Dessein, G. An experimental study on the effect of high-pressure coolant on chip fragmentation during the turning of stainless steel. Int. J. Adv. Manuf. Technol. 2019, 105, 905-918. [CrossRef]

15. Sivaiah, P.; Chakradhar, D. Effect of cryogenic coolant on turning performance characteristics during machining of 17-4 PH stainless steel: A comparison with MQL, wet, dry machining. CIRP J. Manuf. Sci. Technol. 2018, 21, 86-96. [CrossRef]

16. Ning, J.; Nguyen, V.; Huang, Y.; Hartwig, K.T.; Liang, S.Y. Inverse determination of Johnson-Cook model constants of ultra-fine-grained titanium based on chip formation model and iterative gradient search. Int. J. Adv. Manuf. Technol. 2018, 99, 1131-1140. [CrossRef]

17. Ning, J.; Nguyen, V.; Liang, S.Y. Analytical modeling of machining forces of ultra-fine-grained titanium. Int. J. Adv. Manuf. Technol. 2010, 101, 627-636. [CrossRef]

18. Korkmaz, M.E.; Günay, M. Finite Element Modelling of Cutting Forces and Power Consumption in Turning of AISI 420 Martensitic Stainless Steel. Arab. J. Sci. Eng. 2018, 43, 4863-4870. [CrossRef]

19. Galanis, N.I.; Manolakos, D.E. Finite element analysis of the cutting forces in turning of femoral heads from AISI 3161 stainless steel. Lect. Notes Eng. Comput. Sci. 2014, 2, 1232-1237.

20. Koyee, R.D.; Schmauder, S.; Heisel, U.; Eisseler, R. Numerical modeling and optimization of machining duplex stainless steels. Prod. Manuf. Res. 2015, 3, 36-83. [CrossRef]

21. Liu, G.; Huang, C.; Zou, B.; Wang, X.; Liu, Z. Surface integrity and fatigue performance of 17-4PH stainless steel after cutting operations. Surf. Coat. Technol. 2016, 307, 182-189. [CrossRef]

22. Pereira, O.; Rodriquez, A.; Barreiro, J.; Fernandez-Abia, A.I.; Lopez de Lacalle, L.N. Nozzle design for combined use of MQL and cryogenic gas in machining. Int. J. Precis. Eng. Manuf.-Green Technol. 2017, 4, 87-95. [CrossRef]

23. CheHaron, C.H.; Ginting, A.; Arshad, H. Performance of alloyed uncoated and CVD-coated carbide tools in dry milling of titanium alloy Ti-6242S. J. Mater. Process. 2007, 185, 77-82.

24. Ortega, N.; Martynenko, V.; Perez, D.; Krahmer, D.M.; Lopez de Lacalle, L.N.; Ukar, E. Abrasive Disc Performance in Dry-Cutting of Medium-Carbon Steel. Metals 2020, 10, 538. [CrossRef]

25. Egea, A.J.S.; Martynenko, V.; Krahmer, D.M.; Lopez de Lacalle, L.N.; Benitez, A.; Genovese, G. On the Cutting Performance of Segmented Diamond Blades when Dry-Cutting Concrete. Materials 2018, 11, 264. [CrossRef]

26. Nouari, M.; Ginting, A. Wear characteristics and performance of multi-layer CVD-coated alloyed carbide tool in dry end milling of titanium alloy. Surf. Coat. Technol. 2006, 200, 5663-5676. [CrossRef] 
27. Maruda, R.W.; Krolczyk, G.M.; Niesłony, P.; Krolczyk, J.B.; Legutko, S. Chip formation zone analysis during the turning of austenitic stainless steel 316L under MQCL cooling condition. Procedia Eng. 2016, 149, $297-304$. [CrossRef]

28. Maruda, R.W.; Krolczyk, G.M.; Feldshtein, E.; Pusavec, F.; Szydlowski, M.; Legutko, S.; Sobczak-Kupiec, A. A study on droplets sizes, their distribution and heat exchange for minimum quantity cooling lubrication (MQCL). Int. J. Mach. Tools Manuf. 2016, 100, 81-92. [CrossRef]

29. Krolczyk, G.M.; Maruda, R.W.; Krolczyk, J.B.; Wojciechowski, S.; Mia, M.; Nieslony, P.; Budzik, G. Ecological trends in machining as a key factor in sustainable production-A review. J. Clean. Prod. 2019, 218, 601-615. [CrossRef]

30. Korkmaz, M.E.; Yaşar, N.; Günay, M. Numerical and experimental investigation of cutting forces in turning of Nimonic 80A superalloy. Eng. Sci. Technol. Int. J. 2020, 23, 664-673. [CrossRef]

31. Statnikov, R.B.; Statnikov, A.R. The Parameter Space Investigation Method Toolkit; Artech House: Boston, MA, USA, 2011.

32. Jemielniak, K. Obróbka Skrawaniem: Podstawy, Dynamika, Diagnostyka; OWPW: Warszawa, Poland, 2018. (In Polish)

33. Ahmed, Y.S.; Paiva, J.M.; Bose, B.; Veldhuis, S.C. New observations on built-up edge structures for improving machining performance during the cutting of superduplex stainless steel. Tribol. Int. 2019, 137, $212-227$. [CrossRef]

34. Michailidis, N. Variations in the cutting performance of PVD-coated tools in milling Ti6Al4V, explained through temperature-dependent coating properties. Surf. Coat. Technol. 2016, 304, 325-329. [CrossRef]

35. Liu, G.; Huang, C.; Su, R.; Özel, T.; Liu, Y.; Xu, L. 3D FEM simulation of the turning process of stainless steel 17-4PH with differently texturized cutting tools. Int. J. Mech. Sci. 2019, 155, 417-429. [CrossRef]

(C) 2020 by the authors. Licensee MDPI, Basel, Switzerland. This article is an open access article distributed under the terms and conditions of the Creative Commons Attribution (CC BY) license (http://creativecommons.org/licenses/by/4.0/). 